\title{
Natural History and Treatment of Brown's Syndrome: Long-Term Experience
}

\author{
Pedro Filipe Rodrigues*, Raquel Seldon, Gabriela Varandas, Maria Lourdes Vieira \\ Instituto de Oftalmologia Dr. Gama Pinto, Lisbon, Portugal \\ Email: *pedrorodrigues17@hotmail.com
}

How to cite this paper: Rodrigues, P.F., Seldon, R., Varandas, G. and Vieira, M.L. (2018) Natural History and Treatment of Brown's Syndrome: Long-Term Experience. Open Journal of Ophthalmology, 8 , 232-240.

https://doi.org/10.4236/ojoph.2018.84027

Received: October 22, 2018

Accepted: November 19, 2018

Published: November 23, 2018

Copyright (c) 2018 by authors and Scientific Research Publishing Inc. This work is licensed under the Creative Commons Attribution International License (CC BY 4.0).

http://creativecommons.org/licenses/by/4.0/

(c) (i) Open Access

\begin{abstract}
Purpose: Brown's Syndrome (BS) is a restrictive strabismus characterized by a limitation of elevation in adduction. Several etiologies have been described, usually involving the superior oblique muscle. Spontaneous improvement has been reported in several studies, so surgery is reserved for a minority of cases. Our purpose is to review the characteristics, natural history and treatment of this pathology and present the experience of the Instituto de Oftalmologia Dr. Gama Pinto (IOGP). Methods: A consecutive retrospective series of BS patients seen at the Strabismus Department of IOGP between 1983 and 2014 was reviewed. All patients with complete clinical data were included in this study. The epidemiologic characteristics, clinical features, treatment, and clinical progression were reviewed. Results: Thirty-nine cases were selected, with a mean age at first diagnosis of 6.5 years. Of the thirty-nine cases, 6 were iatrogenic and the remainder idiopathic. Thirty-six cases were followed for a mean period of 6.1 years. Surgical intervention for BS was performed in 11 patients, using different approaches. Of these, 9 cases were considered successful. The remaining 25 cases were kept under observation without surgery, of which 17 showed spontaneous improvement and the other 7 remained unchanged. Conclusions: The surgical success rate was $82 \%$, which demonstrates the good efficacy of the surgery despite the complexity and variety of pathophysiological mechanisms of the syndrome. In the patients kept under observation there was spontaneous improvement in $68 \%$, confirming that a conservative approach seems to be adequate in most cases.
\end{abstract}

\section{Keywords}

Brown's Syndrome, Extraocular Muscles, Strabismus, Superior Oblique Muscle, Surgery

\section{Introduction}

Brown's Syndrome (BS) is a type of restrictive strabismus that presents with a 
limitation of elevation in adduction and a positive forced duction test [1] [2] [3] [4] [5]. It can be classified into mild, moderate (if a downshoot in adduction is present) and severe forms (if hypotropia in the primary position is present) [6].

Binocular function is usually preserved, even in severe cases, via a compensatory anomalous head position [5]. The presence of amblyopia is uncommon, varying between $4 \%$ and $25 \%$ of the cases, with lack of fusion as the greatest risk factor [7].

Brown [8] originally considered that the syndrome was caused by a shortening of the tendon sheath of the superior oblique muscle (SO). However, since then, different etiologies have been found, either based on SO abnormalities [3] [9]-[14], anomalous ligaments [13] [15] or conditions affecting other extraocular muscles [13]. It has even been suggested that BS could be included in the denominated Congenital Cranial Denervation Diseases [16], which would help to explain the high frequency of iatrogenic BS after surgical correction of the cranial nerve IV paralysis [11] [17]. However, a definitive etiological diagnosis is not possible without magnetic resonance imaging or exploratory surgery, so the disease is classified as idiopathic in most cases. Traumatic, inflammatory [18] [19] [20] or tumoral [21] entities should be considered and excluded.

No consensus has been reached regarding the best surgical treatment, but surgical intervention of the SO is the current mainstay. Tenotomies and tenectomies are popular because of their simplicity, but are less predictable and have a higher incidence of consecutive SO paresis than lengthening techniques [3] [22]. The purpose of the latter techniques is to lengthen the tendon without causing consecutive paresis and, ideally, to do so in a reversible way.

One popular lengthening technique is SO weakening with a bridge suture technique, between 3 and $8 \mathrm{~mm}$. It is an effective and safe procedure but may be associated with local fibrosis, causing late undercorrections [23] [24].

An alternative to this technique is the use of a silicone band, that can be more stable but is also associated with complications, including consecutive paralysis, adhesion of the band to the adjacent tissues and spontaneous implant extrusion [24] [25] [26] [27].

Surgical correction is usually not necessary, as spontaneous improvement is described in $6 \%$ to $90 \%$ of cases, depending on the studies [5] [12] [28] [29] [30]. Therefore, a conservative approach is usually recommended [31] [32].

In this study, we analyze the cases of Brown's Syndrome of our department and report their clinical progression and outcome.

\section{Patients and Methods}

The cases diagnosed as Brown's Syndrome in the Strabismus Department of Instituto de Oftalmologia Dr. Gama Pinto between 1983 and 2014 were retrospectively reviewed. The study was conducted in accordance with the tenets of the Declaration of Helsinki and approved by the Ethics Commission for Healthcare of Instituto de Oftalmologia Dr. Gama Pinto. Informed consent was obtained from all participants or their parents. 
Data was collected, namely epidemiology, diagnosis and follow-up dates, extraocular motility, ocular deviations, anomalous head position, visual acuity, refraction, and treatment.

The deviations were measured using the prismatic Cover Test.

Visual acuity was evaluated with Snellen optotypes scale, Snellen EE scale or Sheridan test, according to age and cooperation of the patient [33].

Brown's Syndrome was diagnosed when an incomitant strabismus affecting elevation in adduction was present.

Surgical plans were made at the discretion of the surgeon. All surgeries were performed by the same surgeon over this 31 years period.

\section{Results}

We reviewed 39 cases of BS. Every case was included in the study, considering that complete data was present in at least 4 moments: at diagnosis, pre-operatively, post-operatively and final observation. However, when analyzing the natural history, cases with a follow-up inferior to 1 year were excluded.

Six of the cases were iatrogenic, consecutive to SO tuck surgery in the context of congenital IV cranial nerve paralysis. In the remaining 33 cases, no defined etiology and no systemic causes or hereditary patterns were found.

Because of the inherent differences between iatrogenic and idiopathic cases, they will be described separately. Population characteristics may be found in Table 1.

Some cases of idiopathic BS presented with ocular deviation in primary position, as shown in Table 2. Compensatory head position was present in 15 cases, including 4 cases with tilted head to the affected side, 3 with chin elevation, 1 with a head turn to the opposite side and 7 with a combination of the aforementioned positions.

All 8 cases diagnosed with amblyopia had horizontal deviations in the primary position, anisometropia or nystagmus, in addition to BS. Treatment with optical correction and occlusion was prescribed, resulting in complete recovery in 7 cases.

Table 1. Population demographic and clinical data according to etiology.

\begin{tabular}{ccccccc}
\hline \multirow{2}{*}{ Characteristic } & \multicolumn{3}{c}{ Idiopathic group } & \multicolumn{3}{c}{ Iatrogenic group } \\
\cline { 2 - 6 } & OD & OS & OU & OD & OS & OU \\
\hline Laterality & $17(52 \%)$ & $14(42 \%)$ & $2(6 \%)$ & $2(33 \%)$ & $3(50 \%)$ & $1(17 \%)$ \\
& Male & Female & Male & Female \\
Gender & $13(39 \%)$ & $20(61 \%)$ & $4(67 \%)$ & $2(33 \%)$ \\
& Mean $\pm \mathrm{SD}$ & {$[$ Min - Max $]$} & Mean \pm SD & {$[$ Min - Max] } \\
AgeDiag & $5.8 \pm 8.6$ & {$[1-55]$} & $6.5 \pm 3.3$ & {$[4-13]$} \\
& Present & Absent & Present & Absent \\
AHP & $15(45.5 \%)$ & $18(54.5 \%)$ & 0 & $6(100 \%)$ \\
Amblyopia & $8(24 \%)$ & $25(76 \%)$ & 0 & $6(100 \%)$ \\
\hline
\end{tabular}

Age Diag—age at diagnosis; AHP—abnormal head position; OD—right eye; OS—left eye; OU—both eyes. 
Table 2. Ocular deviations in the idiopathic group

\begin{tabular}{|c|c|c|c|c|c|c|c|c|c|}
\hline Deviation & Ortho & $\begin{array}{c}\mathrm{Ht} \\
<10 \mathrm{D}\end{array}$ & $\begin{array}{c}\mathrm{Ht} \\
\geq 10 \mathrm{D}\end{array}$ & $\begin{array}{c}\text { ET } \\
<10 \mathrm{D}\end{array}$ & $\begin{array}{c}\text { ET } \\
10-25 \mathrm{D}\end{array}$ & $\begin{array}{c}\mathrm{ET} \\
>25 \mathrm{D}\end{array}$ & $\mathrm{XT}$ & $\begin{array}{c}\mathrm{Ht} \\
+\mathrm{ET}\end{array}$ & $\begin{array}{c}\mathrm{Ht} \\
+\mathrm{XT}\end{array}$ \\
\hline $\begin{array}{l}\mathrm{N}= \\
(\%)\end{array}$ & $\begin{array}{c}10 \\
(30.3 \%)\end{array}$ & $\begin{array}{c}5 \\
(15.2 \%)\end{array}$ & $\begin{array}{c}3 \\
(9.1 \%)\end{array}$ & $\begin{array}{c}1 \\
(3 \%)\end{array}$ & $\begin{array}{c}3 \\
(9.1 \%)\end{array}$ & $\begin{array}{c}1 \\
(3 \%)\end{array}$ & $\begin{array}{c}1 \\
(3 \%)\end{array}$ & $\begin{array}{c}4 \\
(12.1 \%)\end{array}$ & $\begin{array}{c}5 \\
(15.2 \%)\end{array}$ \\
\hline
\end{tabular}

Ortho—orthotropia; Ht—hypotropia; ET—esotropia; XT—exotropia.

Three out of the 33 idiopathic cases abandoned follow-up within the period of 1 year, leaving a total of 30 cases that were followed for an average time of 6 years ( 1 - 16 years).

Surgical intervention was performed in 9 cases presenting with persistent hypotropia of at least $6 \mathrm{D}$ in the primary position. The age of intervention varied between 3 and 55 years, with a mean of 9 years and a median of 5 years.

The surgical goal was to correct the ocular deviation in the primary position and consequently to reduce or eliminate the associated torticollis.

Considering the idiopathic BS cases (cases 1 - 9 of Table 3), the surgery was successful in 7 cases. One case had complaints of diplopia several years later (case 4) and it was necessary to reoperate in 1 case, in order to perform a contralateral superior rectus weakening (case 6). Of the 2 unsuccessful cases: one was a late-onset BS with severe vertical diplopia that could not be corrected (case 9); and one was a child with a positive forced ductions test that was corrected right after the end of the surgery but that maintained the restriction of movements in the postoperative period (case 3).This patient is still under observation.

Twenty-one cases were kept under observation, with spontaneous improvement occurring in $13(62 \%)$. This was shown by a progressive reduction of the restriction in supra-adduction and, in some cases, with near resolution of the limitation, especially during adolescence. Only 1 case showed a worsening of the condition, but without the development of amblyopia or abnormal head position, so surgical intervention was not performed. The remaining cases showed clinical stability. The characteristics of the idiopathic cases that showed improvement are compared in Table 4. Spontaneous improvement seems to be less likely in the presence of amblyopia. Although without statistical differences between the groups, horizontal deviations seem to be associated with a lower degree of spontaneous improvement.

Only 2 in 6 iatrogenic cases needed surgical correction, specifically, the reversion of the SO tuck that caused the condition. The surgery was successful in both cases (Table 3). The remaining 4 cases improved spontaneously, without the need for intervention.

\section{Discussion}

We analyzed 39 cases of BS with different grades of severity and associated characteristics. We did not classify the cases as congenital or acquired due to difficulties in establishing the age of manifestation of the disease. 
Table 3. Surgeries performed and pre and post-op characteristics.

\begin{tabular}{|c|c|c|c|c|c|c|c|c|c|}
\hline \multirow{2}{*}{$\mathrm{N}$} & \multicolumn{4}{|c|}{ Pre-op } & \multirow{2}{*}{ Surgery } & \multicolumn{4}{|c|}{ Post-op } \\
\hline & VD & HD & AHP & $\mathrm{Cl}$ & & VD & HD & AHP & $\mathrm{Cl}$ \\
\hline 1 & 6 & 0 & $\mathrm{P}$ & 3 & SO bridge suture $(8 \mathrm{~mm})$ & 0 & 0 & A & 0 \\
\hline 2 & 10 & $14(\mathrm{XT})$ & $\mathrm{P}$ & 3 & SO bridge suture $(7 \mathrm{~mm})$ & 2 & $4(\mathrm{XT})$ & A & 3 \\
\hline 3 & 0 & $30(\mathrm{ET})$ & $\mathrm{P}$ & 3 & SO bridge suture $(6 \mathrm{~mm})$ & 0 & 30 & $\mathrm{P}$ & 3 \\
\hline 4 & 18 & $4(\mathrm{XT})$ & $\mathrm{P}$ & 3 & SO bridge suture $(6 \mathrm{~mm})+$ contralateral superior rectus recession & 6 & $4(\mathrm{XT})$ & $\mathrm{P}$ & 3 \\
\hline 5 & 6 & $8(\mathrm{ET})$ & A & 3 & SO bridge suture $(6 \mathrm{~mm})+$ contralateral superior rectus recession & 2 & $4(\mathrm{ET})$ & A & 1 \\
\hline 6 & 6 & $16(\mathrm{ET})$ & A & 3 & $\begin{array}{l}\text { SO bridge suture }(4 \mathrm{~mm})+\text { ipsilateral superior rectus recession } \\
+ \text { contralateral inferior rectus recession }\end{array}$ & 4 & $4(\mathrm{ET})$ & A & 1 \\
\hline 7 & 8 & 0 & A & 3 & SO silicone band $(8 \mathrm{~mm})+$ contralateral superior rectus recession & 0 & 0 & A & 1 \\
\hline 8 & 0 & $25(\mathrm{ET})$ & A & 2 & $\begin{array}{l}\text { Bilateral botulinum toxin in the medial rectus and subsequent bilateral medial } \\
\text { rectus recession and posterior fixation suture }+ \text { steroid injection in affected SO }\end{array}$ & 0 & 8 & A & 1 \\
\hline 9 & 14 & $8(\mathrm{XT})$ & A & 3 & $\begin{array}{l}\text { SO bridge suture }(8 \mathrm{~mm})+\text { ipsilateral lateral rectus recession }+ \text { contralateral } \\
\text { inferior oblique tenectomy + contralateral superior rectus recession }\end{array}$ & 6 & 0 & A & 3 \\
\hline 10 & 8 & 0 & A & 3 & Tuck Reversion & 0 & 0 & A & 0 \\
\hline 11 & 8 & $6(\mathrm{XT})$ & A & 3 & $\begin{array}{l}\text { Tuck Reversion + contralateral inferior oblique anteroposition to Fink's point. } \\
\text { Subsequently bilateral lateral rectus recession was performed. }\end{array}$ & 0 & $10(\mathrm{XT})$ & A & 0 \\
\hline 12 & 0 & $16(\mathrm{ET})$ & A & 2 & $\begin{array}{l}\text { Bilateral botulinum toxin in the medial rectus and } \\
\text { subsequent medial rectus recession with posterior fixation suture }\end{array}$ & 0 & 0 & A & 0 \\
\hline 13 & 0 & $25(\mathrm{ET})$ & A & 1 & Bilateral botulinum toxin in the medial rectus & 0 & $6(\mathrm{ET})$ & A & 1 \\
\hline 14 & 4 & $25(\mathrm{XT})$ & A & 1 & Bilateral lateral rectus recession & 4 & $10(\mathrm{XT})$ & A & 1 \\
\hline
\end{tabular}

VD—vertical deviation in prism diopters; HD—horizontal deviation in prism diopters (XT-exotropia; ET—esotropia); AHP—abnormal head position (A—absent; P-present); Cl—classification of severity of BS ( 1 = mild, 2 = moderate, $3=$ severe).

Table 4. Comparison of characteristics of idiopathic SB cases with and without spontaneous improvement.

\begin{tabular}{cccc}
\hline & With spontaneous improvement & Without spontaneous improvement & p value \\
\hline Male/Female & $7 / 6$ & $2 / 6$ & 0.195 \\
OD/OS/OU & $8 / 4 / 1$ & $2 / 5 / 1$ & 0.133 \\
With/Without Amblyopia & $1 / 12$ & $5 / 3$ & 0.014 \\
AHP present/absent & $5 / 7$ & $3 / 5$ & 0.596 \\
Age Diag (years) & $4.46 \pm 2.18$ & $4.38 \pm 1.92$ & 0.928 \\
Vert Dev (D) & $3.62 \pm 6.24$ & $2.29 \pm 4.07$ & 0.619 \\
Esotropia (D) & $1.08 \pm 3.88$ & $5.50 \pm 10.41$ & 0.281 \\
Exotropia (D) & $0.92 \pm 3.33$ & $3.75 \pm 10.61$ & 0.377 \\
\hline
\end{tabular}

Discrete variables are presented as the absolute number for each category and comparison is made with the chi-square test. Continuous variables are presented as mean \pm standard deviation and comparison is made with the independent samples T test. Age Diag—age at diagnosis; AHP—abnormal head position; OD—right eye; OS-left eye; OU—both eyes.

We could not find the etiology of the disease, with the exception of the iatrogenic cases, so most cases were considered idiopathic.

Amblyopia was essentially associated with more amblyogenic pathologies (mostly esotropia or exotropia) and had a good therapeutic response. 
Sixty-eight percent of the cases that were kept under observation showed spontaneous improvement, with the remaining maintaining stability. This is consistent with the data found in the literature [5] [34] and strengthens the current recommendation of a conservative approach to these cases.

Despite the good prognosis, it is necessary to be alert to the presence of abnormal head position, which is probably underdiagnosed [35], and had a significant prevalence in our population.

Regarding surgical treatments, the SO bridge suture was the most commonly used technique, because of the effectiveness and predictability described in the literature [23] [24]. The global surgical success was 78\%, confirming the good results of this procedure. This technique was frequently combined with surgery in other muscles and, despite the complexity associated with this kind of procedure, the efficacy was good. Although surgery is not necessary in most cases, it should not be postponed when justified, as it allows for acceptable correction of primary position ocular alignment and the correction of abnormal head position, leading to improvements in quality of life.

Limitations of this study include its retrospective nature and varying times of follow-up that could interfere with the analysis. The surgical intervention was personalized to each patient, making it hard to compare techniques and to report global results.

\section{Conclusion}

In conclusion, our experience seems to confirm that the spontaneous improvement of BS is common. This fact should be considered when evaluating BS. Furthermore, when surgery is required, planning may be complex, but the results are usually good.

\section{Conflicts of Interest}

All authors declare that they have no conflict of interest.

\section{Ethical approval}

All procedures performed were in accordance with the ethical standards of the institutional research committee and with the 1964 Declaration of Helsinki and its later amendments.

\section{Informed Consent}

Informed consent was obtained from all individual participants included in the study.

\section{References}

[1] Brown, H. (1950) Congenital Structural Muscle Anomalies. In: Allen, J., Ed., Strabismus Ophthalmic Symposium, Mosby, St. Louis, 205-236.

[2] Wilson, M.E., Sprague, H. and Parks, M.M. (1989) Brown's Syndrome. Survey of 
Ophthalmology, 34, 153-172. https://doi.org/10.1016/0039-6257(89)90100-8

[3] Von Noorden, G.K. and Olivier, P. (1982) Superior Oblique Tenectomy in Brown's Syndrome. Ophthalmology, 89, 303-309. https://doi.org/10.1016/S0161-6420(82)34787-9

[4] Manley, D.R. and Alvi, R.A. (2011) Brown's Syndrome. Current Opinion in Ophthalmology, 22, 432-440. https://doi.org/10.1097/ICU.0b013e328349b0ca

[5] Wright, K.W. (1999) Brown's Syndrome: Diagnosis and Management. Transactions of the American Ophthalmological Society, 97, 1023-1109.

http://www.pubmedcentral.nih.gov/articlerender.fcgi?artid=1298285\&tool=pmcent $\underline{\text { rez\&rendertype }=\text { abstract }}$

[6] Stager Jr., D.R., Parks, M.M., Stager Sr., D.R. and Pesheva, M. (1999) Long-Term Results of Silicone Expander for Moderate and Severe Brown Syndrome (Brown Syndrome "Plus"). Journal of AAPOS, 3, 328-332. https://doi.org/10.1016/S1091-8531(99)70039-X

[7] Sekeroglu, H.T., Muz, E., Sanac, A.S., Sener, E.C. and Arslan, U. (2013) Amblyopia and Sensory Features at Initial Presentation of Brown Syndrome: An Issue to Recognize. Eye (Lond), 27, 515-518. https://doi.org/10.1038/eye.2012.306

[8] Brown, H. (1974) True and Simulated Superior Oblique Tendon Sheath Syndromes. Australian Journal of ophthalmology, 2, 12-19. https://doi.org/10.1111/j.1442-9071.1974.tb01658.x

[9] Crawford, J.S. (1976) Surgical Treatment of True Brown's Syndrome. American Journal of Ophthalmology, 81, 289-295. https://doi.org/10.1016/0002-9394(76)90242-7

[10] Parks, M.M. (1977) Doyne Memorial Lecture, 1977. The Superior Oblique Tendon. Transactions of the Ophthalmological Societies of the United Kingdom, 97, 288-304.

[11] Helveston, E., Merriam, W., Ellis, F., Shellhamer, R. and Gosling, C. (1982) The Trochlea. A Study of the Anatomy and Physiology. Ophthalmology, 89, 124-133. https://doi.org/10.1016/S0161-6420(82)34835-6

[12] Magalhães, A., Breda, J., Matos, J. and Castro, A. (1991) Síndroma de Brown-apresentação e evolução clínicas. Acta Ophthalmologica, 2, 97-100.

[13] Bhola, R., Rosenbaum, A.L., Ortube, M.C. and Demer, J.L. (2005) High-Resolution Magnetic Resonance Imaging Demonstrates Varied Anatomic Abnormalities in Brown Syndrome. Journal of AAPOS, 9, 438-448. https://doi.org/10.1016/j.jaapos.2005.07.001

[14] Oh, S.Y., Clark, R.A., Velez, F., Rosenbaum, A.L. and Demer, J.L. (2002) Incomitant Strabismus Associated with Instability of Rectus Pulleys. Investigative Ophthalmology \& Visual Science, 43, 2169-2178.

[15] Parks, M.M. and Brown, M. (1975) Superior Oblique Tendon Sheath Syndrome of Brown. American Journal of Ophthalmology, 79, 82-86. https://doi.org/10.1016/0002-9394(75)90460-2

[16] Coussens, T. and Ellis, F. (2015) Considerations on the Etiology of Congenital Brown Syndrome. Current Opinion in Ophthalmology, 26, 357-361. https://doi.org/10.1097/ICU.0000000000000191

[17] Kaeser, P.F., Klainguti, G. and Kolling, G.H. (2012) Inferior Oblique Muscle Recession with and without Superior Oblique Tendon Tuck for Treatment of Unilateral Congenital Superior Oblique Palsy. Journal of AAPOS, 16, 26-31. https://doi.org/10.1016/j.jaapos.2011.08.012 
[18] Moore, A.T. and Morin, D.J. (1985) Bilateral Acquired Inflammatory Brown's Syndrome. Journal of Pediatric Ophthalmology and Strabismus, 22, 26-30.

[19] Roifman, C.M., Lavi, S., Moore, A.T., Morin, D.J., Stein, L.D. and Gelfand, E.W. (1984) Tenosynovitis of the Superior Oblique Muscle (Brown syndrome) Associated with Juvenile Rheumatoid Arthritis. The Journal of Pediatrics, 106, 7-9.

[20] Hermann, J.S. (1978) Acquired Brown's Syndrome of Inflammatory Origin. Archives of Ophthalmology, 96, 1228-1232. https://doi.org/10.1001/archopht.1978.03910060062012

[21] Biedner, B., Monos, T., Frilling, F., Mozes, M. and Yassur, Y. (1988) Acquired Brown's Syndrome Caused by Frontal Sinus Osteoma. Journal of Pediatric Ophthalmology and Strabismus, 25, 226-229.

[22] Parks, M.M. and Eustis, H.S. (1987) Simultaneous Superior Oblique Tenotomy and Inferior Oblique Recession in Brown's Syndrome. Ophthalmology, 94, 1043-1048. https://doi.org/10.1016/S0161-6420(87)33347-0

[23] Dyer, J. (1970) Superior Oblique Tendon Sheath Syndrome. Annals of Ophthalmology, 2, 790-792.

[24] Awadein, A. and Gawdat, G. (2012) Comparison of Superior Oblique Suture Spacers and Superior Oblique Silicone Band Expanders. Journal of AAPOS, 16, 131-135. https://doi.org/10.1016/j.jaapos.2011.11.011

[25] Keskinbora, K. (2007) Long-Term Outcome of a Silicone Expander for Brown's Syndrome. Journal of Pediatric Ophthalmology and Strabismus, 44, 163-169.

[26] Cho, Y.A., Kim, S. and Graef, M.H. (2006) Surgical Outcomes in Correction of Brown Syndrome. Korean Journal of Ophthalmology, 20, 33-40. https://doi.org/10.3341/kjo.2006.20.1.33

[27] Wright, K.W. (2000) Results of the Superior Oblique Tendon Elongation Procedure for Severe Brown's Syndrome. Transactions of the American Ophthalmological Society, 98, 41-50.

http://www.pubmedcentral.nih.gov/articlerender.fcgi?artid=1298210\&tool=pmcent rez\&rendertype $=$ abstract

[28] Kaban, T.J., Smith, K., Orton, R.B., Noel, L.P., Clarke, W. and Cadera, W. (1993) Natural History of Presumed Congenital Brown Syndrome. Archives of Ophthalmology, 111, 943-946. https://doi.org/10.1001/archopht.1993.01090070061020

[29] Gregersen, E. and Rindziunski, E. (1993) Brown's Syndrome. Acta Ophthalmologica, 71, 371-376. https://doi.org/10.1111/j.1755-3768.1993.tb07150.x

[30] Dawson, E., Barry, J. and Lee, J. (2009) Spontaneous Resolution in Patients with Congenital Brown Syndrome. Journal of AAPOS, 13, 116-118. https://doi.org/10.1016/j.jaapos.2008.09.007

[31] Von Noorden, G.K. and Campos, E.C. (2002) Binocular Vision and Ocular Motility. 6th Edition, Mosby, St. Louis.

[32] Wilson, M.E., Sinatra, R. and Saunders, R. (1995) Downgaze Restriction after Placement of Superior Oblique Tendon Spacer for Brown Syndrome. Journal of Pediatric Ophthalmology and Strabismus, 32, 29-36.

[33] Brant, J. and Nowotny, M. (1976) Testing of Visual Acuity in Preschool Children. Developmental Medicine \& Child Neurology, 18, 568-576. https://doi.org/10.1111/j.1469-8749.1976.tb04203.x

[34] Sorrentino, D. and Warman, R. (2014) Clinical Progression of Untreated Bilateral Brown Syndrome. Journal of AAPOS, 18, 156-158.

https://doi.org/10.1016/j.jaapos.2013.12.004 
[35] Erkan Turan, K., Taylan Sekeroglu, H., Koc, I., Kilic, M. and Sanac, A.S. (2017) The Frequency and Causes of Abnormal Head Position Based on an Ophthalmology Clinic's Findings: Is It Overlooked? European Journal of Ophthalmology, 27, 491-494. https://doi.org/10.5301/ejo.5000908 